\title{
Kinetic and inhibitory study of partially purified lipoxygenase from epilepsy patient's serum
}

\author{
Ahmed Ali Saleh Al-Fayyadh *1, Nashwan Ibrahem Abo Shahine ${ }^{2}$ \\ ${ }^{1 *}$ Ministry of Education, Nineveh Education Directorate, Mosul, Iraq \\ ${ }^{2}$ Department of Chemistry, College of Education for Pure Sciences, University of Mosul, Mosul, Iraq \\ E-mail: ${ }^{1 *}$ ahmedofficer88@gmail.com,${ }^{2}$ nashwan78ibrahem@uomosul.edu.iq \\ (Received July 24, 2020; Accepted August 31, 2020; Available online March 01, 2021) \\ DOI: 10.33899/edusj.2020.127778.1093, @ 2020, College of Education for Pure Science, University of Mosul. \\ This is an open access article under the CC BY 4.0 license (http://creativecommons.org/licenses/by/4.0/).
}

\begin{abstract}
This research was included partially purification of lipoxygenase (LOX) from serum of patients with epilepsy using ammonium sulfate precipitation, dialysis and ion-exchange chromatography with specific activity $(0.751 \mathrm{U} / \mathrm{mg}),(0.935 \mathrm{U} / \mathrm{mg})$ and $(2.60 \mathrm{U} / \mathrm{mg})$ respectively. Optimum conditions for enzyme activity were determined. The best enzyme activity was showed at 7 minutes of incubation time, 3 minutes of reaction time, $\mathrm{pH}=7$, temperature $40 \mathrm{C}^{\circ}$ and finally substrate concentration (linoleic acid) was $(1.2 \mathrm{mmol} / \mathrm{L})$. By applying Michaelis-Menten and Lineweaver-Burk Equations, Michaelis-Menten constant $(\mathrm{km})$ and Vmax values were found $0.3(\mathrm{mM})$ and $(0.9 \mathrm{U} / \mathrm{ml})$ respectively. Also this study included the effect of some antiepileptic drugs such as valproic acid, carbamazepine and acetozolamide. Acetazolamide showed the highest inhibition of lipooxygenase activity(\%96.2), valproic acid(95.6) and Carbamazapine(\%95.1). Inhibition type was studied and the result showed noncompetitive inhibition by using Lineweaver-Burke plot for all above drugs.
\end{abstract}

Keyword: Epilepsy, Lipoxygenase, inhibition, purification, antiepileptic drugs

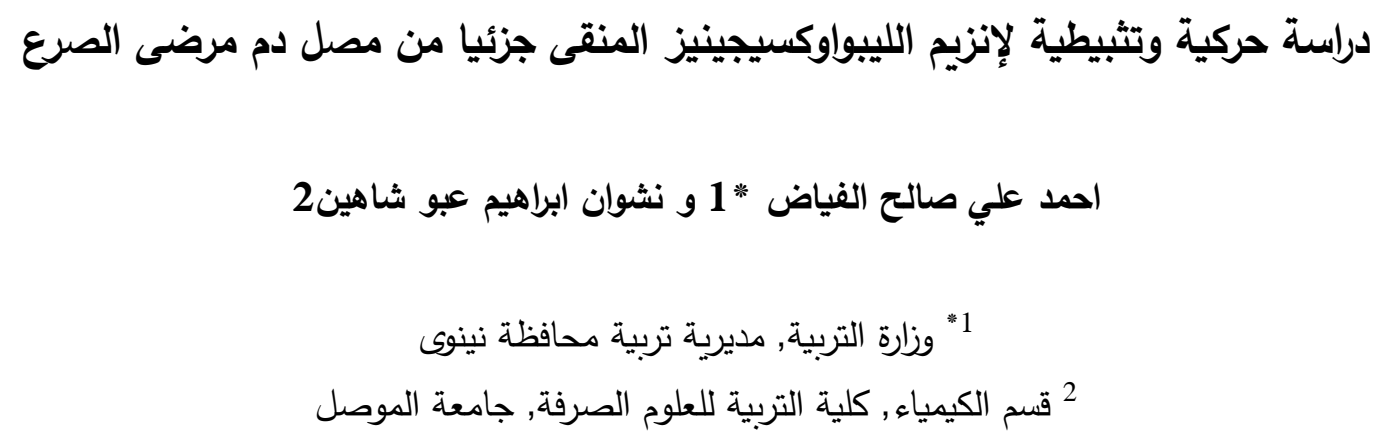

الخلاصة

تضمنت الدراسة تتقية إنزيم الليبواوكسيجنيز جزئيا من مصل دم المرضى المصابين بالصرع باستخدام تقنية الترسيب بكبريتات الامونيوم

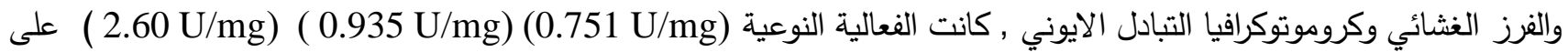
التوالي. حددت الظروف المثلى لفعالية الانزيم واظهرت النتائج ان اعلى فعالية للانزيم عند الدقيقة السابعة من زمن الحضن , وان

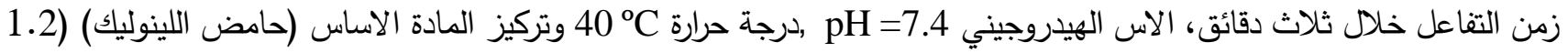
ملي مول/لتر), بتطبيق معادلتي ميكيلس مينتن ولاينويغر - بيرك، ثابت ميكلس مينتون والسرعة القصوى 0.3mM و 0.9 U/ ml 
على التوالي . كذلك تضمنت الدراسة دراسة تأثير بعض العقاقير المضادة للصرع مثل حامض فالبرويك , كاربامازابين , الاسيتوزولاميد.

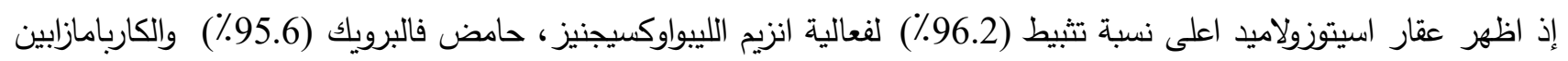
(95.1\%). تمت دراسة نوع التثبيط وأظهرت النتائج باستخدام معادلة لينويفر - برك ان التثبيط غير تتافسي ولجميع العقاقير أعلاه.

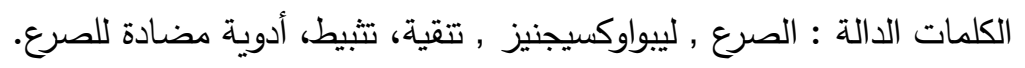

Introduction المقدمة

الصرع هو اضطراب شائع في الجهاز العصبي المركزي يصيب الذكور والاناث بجميع الاعمار واكثر شيوعا في الاطفار وكبار

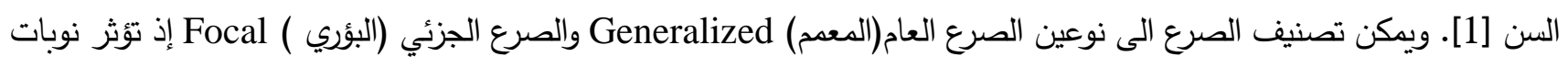

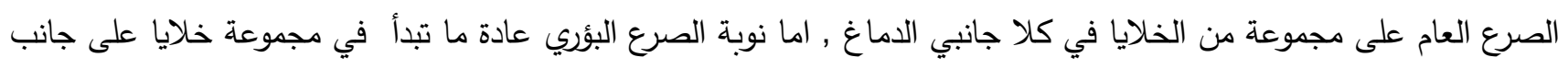
واحد من الدماغ , وتتشأ نوبات الصرع عن طريق الثذوذ او التزامن او الافراط في النشاط العصبي في الدماغ مما يسبب اضطراباً

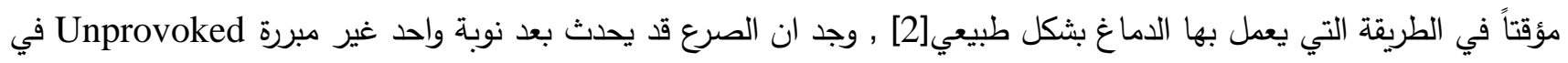

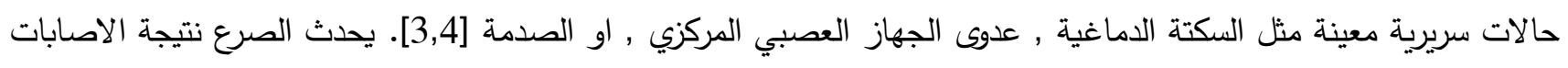

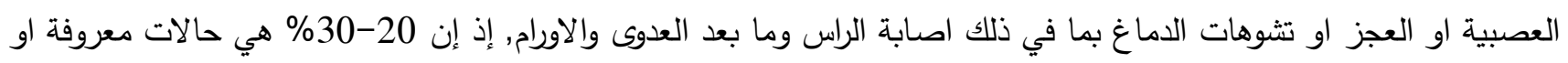

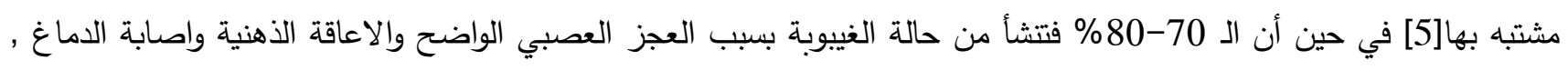
العوامل الوراثية (الجينية) تلعب دورا رئيساً كمسبب للصرع مجهول السبب [6,7]. إن خيارات العلاج المتاحة والمتوفرة هي الادوية

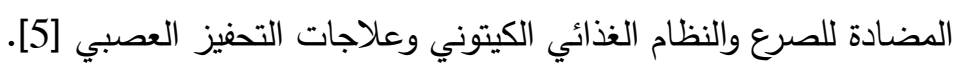
انزيمات LOXs Lipoxygenases تتتشر على نطاق واسع في النباتات والحيوانات. تحفز LOXs إضافة ذرتي اوكسجين الى الاحماض الدهنية المتعدد غير المشبعة

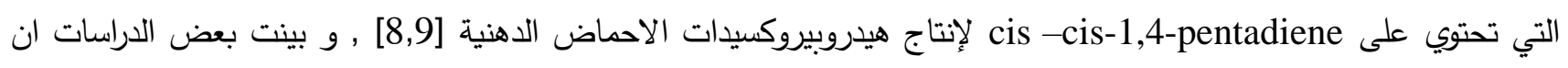

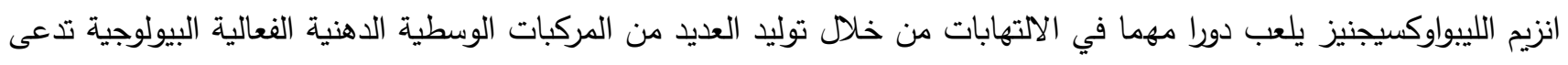

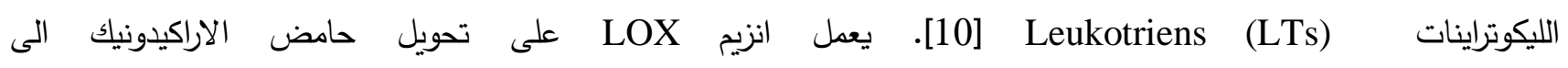

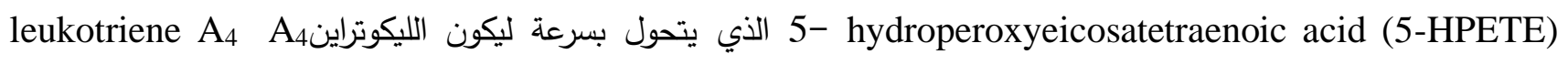

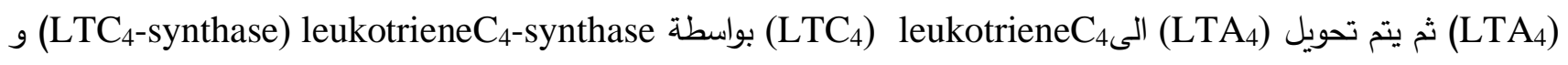

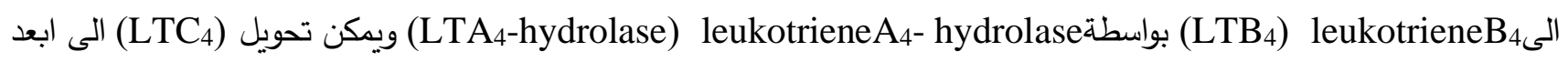

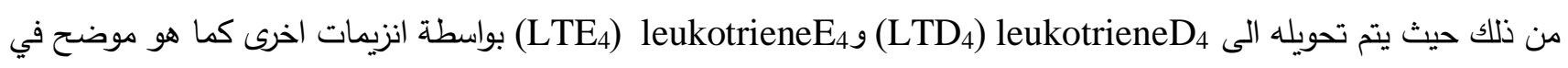
الثكل (1) [11] تم العثور على زيادة في تركيز LTD4 ي خلل الحاجز الدموي الدماغي [12] الذي يرتبط به التهاب الاعصاب ومرض الصرع [13]. وان مثبطات مساري Lipoxygenase\Cycloxygenase LOXICOX تثير الى انخفاض اليكوتراينات

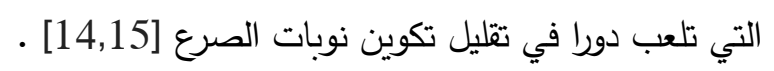




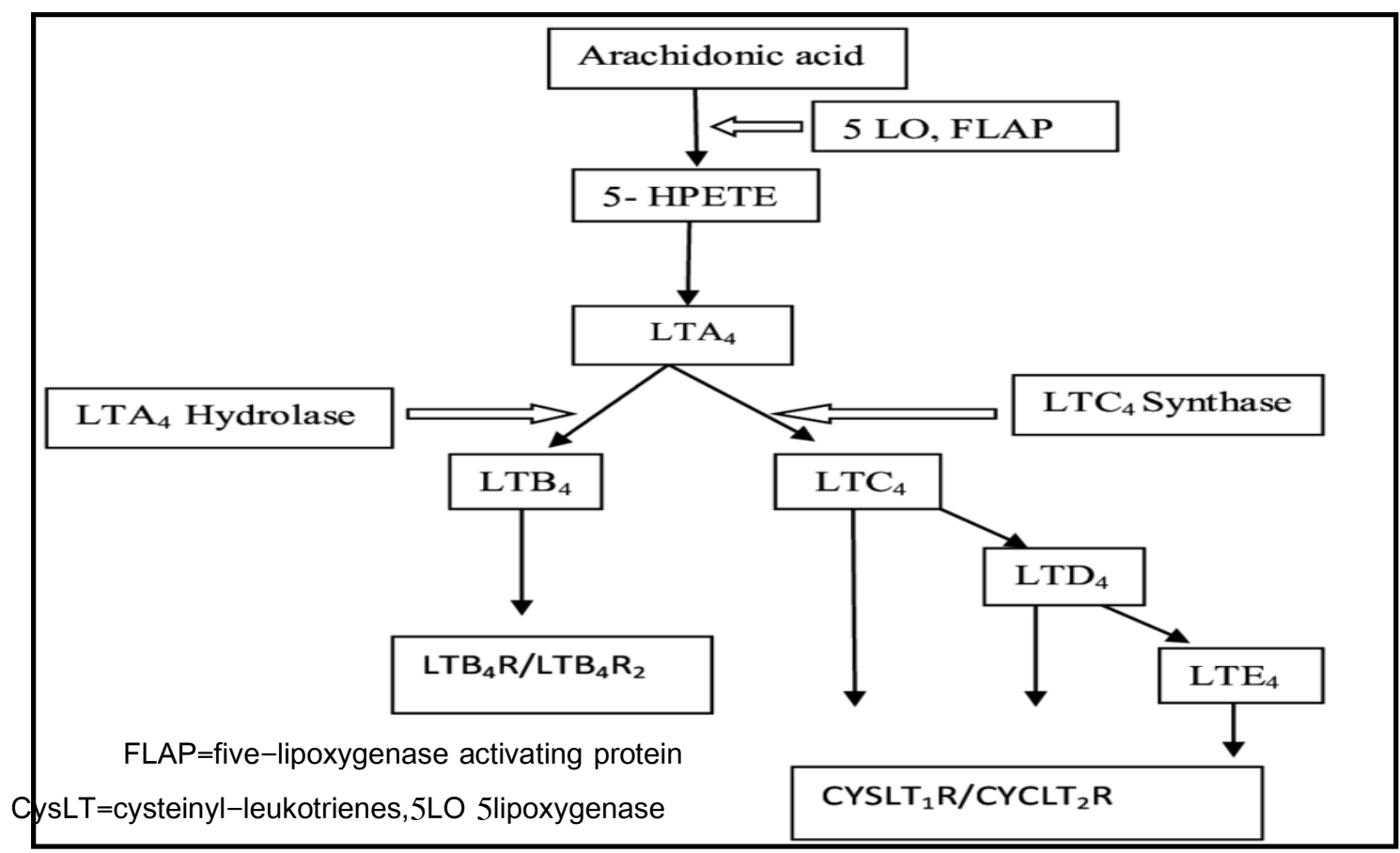

شكل (1): التخليق الحيوي لليكوتراينات [16]

Aim of the research الهذف من البحث تنقية انزيم الليبواوكسيجينيز من مصل دم مرضى الصرع ودراسة الظروف المثلى المؤثرة على الفعالية ومن ثم الكثف عن تأثير بعض الادوية المضادة للصرع على الفعالية الانزيمية

Materials and methods المواد وطرائق العمل

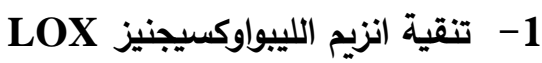

تحضير العينة : جمعت 10 عينات لمرضى ذكور مصابين بالصرع مشخصين بإشراف طبي في وحدة الجملة العصبية لمستثفى ابن سينا التعليمي في محافظة نينوى بإعمار ( 25 - 45) إذ تم سحب 5 مليليتر من دم كل مصاب ومن ثم وضع في أنابيب اختبار غير حاوية على مضاد تخثر الدم، فصل مصل الدم في جهاز الطرد المركزي فائق السرعة المبرد (Ultra - cooling Centrifuge)

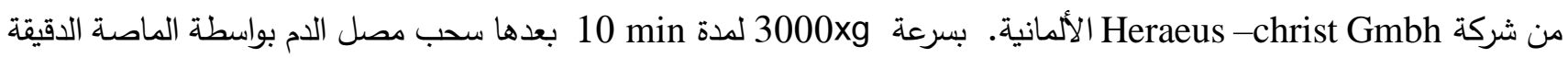
ووضع في أنابيب بلاستيكية جافة , ثم حفظ في بدرجات حرارة 40م [17,18].

البروتين الكلي: قدرت كمية البروتين باتباع طريقة فولن -لاوري Folin -Lowry method المحورة من قبل الباحثين [19]. فعالية انزيم LOX:- قدرت فعالية انزيم الليبواوكسيجنيز المنقى جزئيا من مصل دم مرضى الصرع باتباع طريقة الباحث [20] باستخدام حامض اللينوليك كمادة اساس وبمتابعة الزيادة في الامتصاصية عند طول موجي 234nm الناتجة عن تكوين الدايينات.

اخذ 11 مل من مصل مجموعة من المرضى واجريت عليها خطوات التتقية الآتية : 1- الترسيب بكبريتات الامونيوم: رسب البروتين بتركيز 65\% كبريتات الامونيوم المشبعة بالإضافة التدريجية بعدها ترك بدرجة

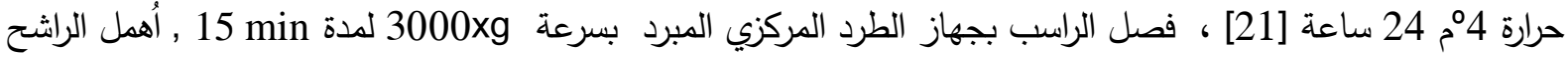


وأخذ الراسب و تم إذابته باقل كمية من محلول الفوسفات المنظم بتركيز 20mmol عند pH = 6.8 , بعدها قُرت كمية البروتين وفعالية الأنزيم.

2- الفرز الغشائي: نقي محلول الراسب البروتيني باستخدام كيس الفرز الغشائي [21] ضد محلول الفوسفات الكنظم عند 6.8 = فترة 24 ساعة في حمام تلجي مع مراعاة تبديل المحلول المنظم كل 5 ساعات , بعدها قُدرت كمية البروتين وفعالية الأنزيم

3- التتقية باستخدام المبادل الايوني السالب DEAE-cellulose A50 [22] : تمت التنقية باستخدام عمود الفصل بأبعاد 2.5x40 cm بإمرار محلول الفوسفات المنظم عند pH=6.8 باستمرار , ثم جمعت الاجزاء بواقع 5 مليليتر بمعدل جريان 60 مل/ساعة, بعدها قُدرت كمية البروتين وفعالية الانزيم فيه.

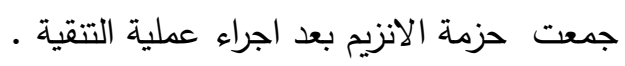

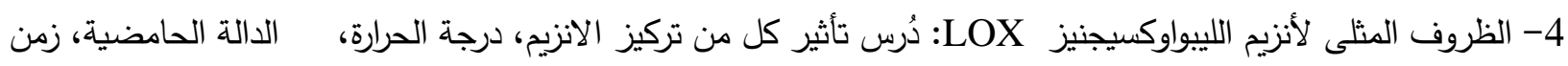

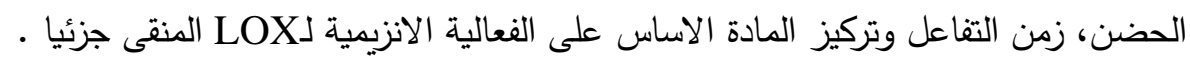
5- تثبيط انزيم LOX: تمت دراسة تأثير بعض العقاقير المضادة للصرع فالبوريك ، كاربامازابين و اسيتولازاميد على فعالية بتحضير تراكيز مختلفة منها (20X اضيف 100 مايكروليتر من المثبط الى عينة الانزيم [23] بعدها قيست الفعالية كما في الفقرة 1.

\section{Results and discussion النتائج والمناقشة} 1 - تنقية انزيم الليبواوكسيجنيز و

يوضح الجدول (1) نتائج تتقية انزيم الليبواوكسيجنيز جزئيا من مصل دم المرضى المصابين بالصرع واظهرت نتائج التنقية بالترسيب

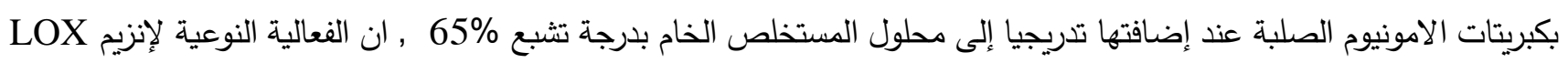

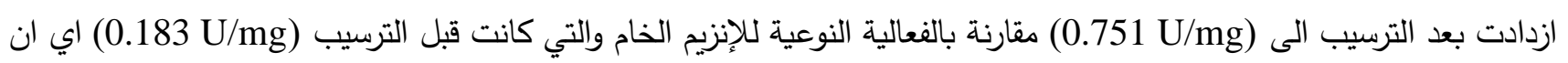

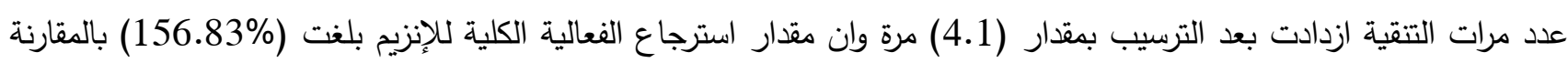

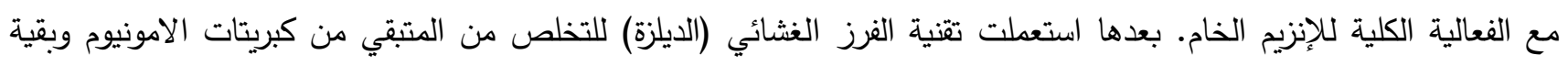

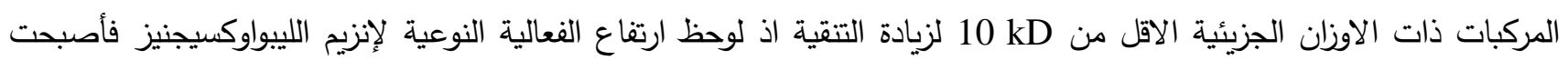
(0.935 U/mg)

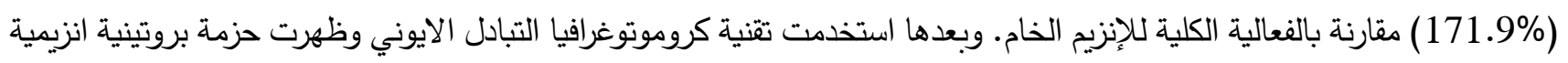

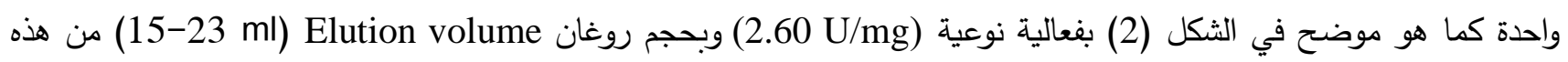

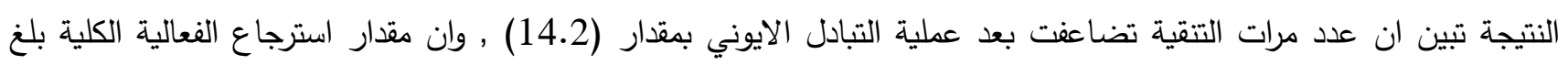
(221.81\%) مما هو عليه في المصل الخام في حين وجد في دراسة نقي فيها الانزيم ان الفعالية النوعية لإنزيم الليبواوكسيجنيز

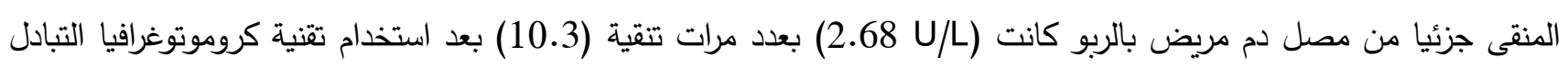

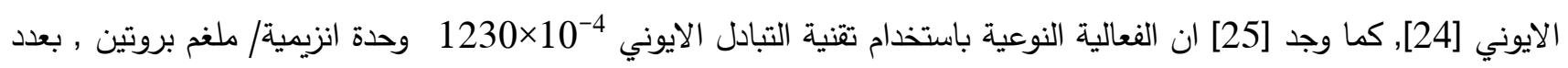
مرات تضاعف 18.08 للإنزيم المنقى من مستخلص قشرة نبات الفستق البري. 


\begin{tabular}{|c|c|c|c|c|c|c|c|c|}
\hline اسنَرجاع & تضاعف & 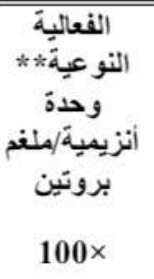 & ألنلية وحلية ألفية & الفعالية & البزروتين & (لثفروتين & الكجيم & خطوات التنقيـة \\
\hline 100 & - & 0.183 & 1.265 & 0.115 & 690.8 & 62.8 & 11 & مصل الدم الخام \\
\hline 156.83 & 4.1 & 0.751 & 1.984 & 0.124 & 264 & 16.5 & 16 & الترسيب بكبريتّات \\
\hline 171.9 & 5.1 & 0.935 & 2.175 & 0.145 & 232.5 & 15.5 & 15 & الفرز الفشاني \\
\hline 221.81 & 14.2 & 2.60 & 2.806 & 0.073 & 107.5 & 2.8 & 38.4 & التبادل الايوني \\
\hline
\end{tabular}

* الوحدة الأنزيمية U : تثير إلى كمية أنزيم الليبواوكسيجنيز الذي يؤكسد مايكرومولاً واحدا من المادة الأساس (حامض اللينوليك) في الدقيقة الواحدة .U/mg: وهي عدد وحدات الانزيم الموجودة في ملغم من البروتين

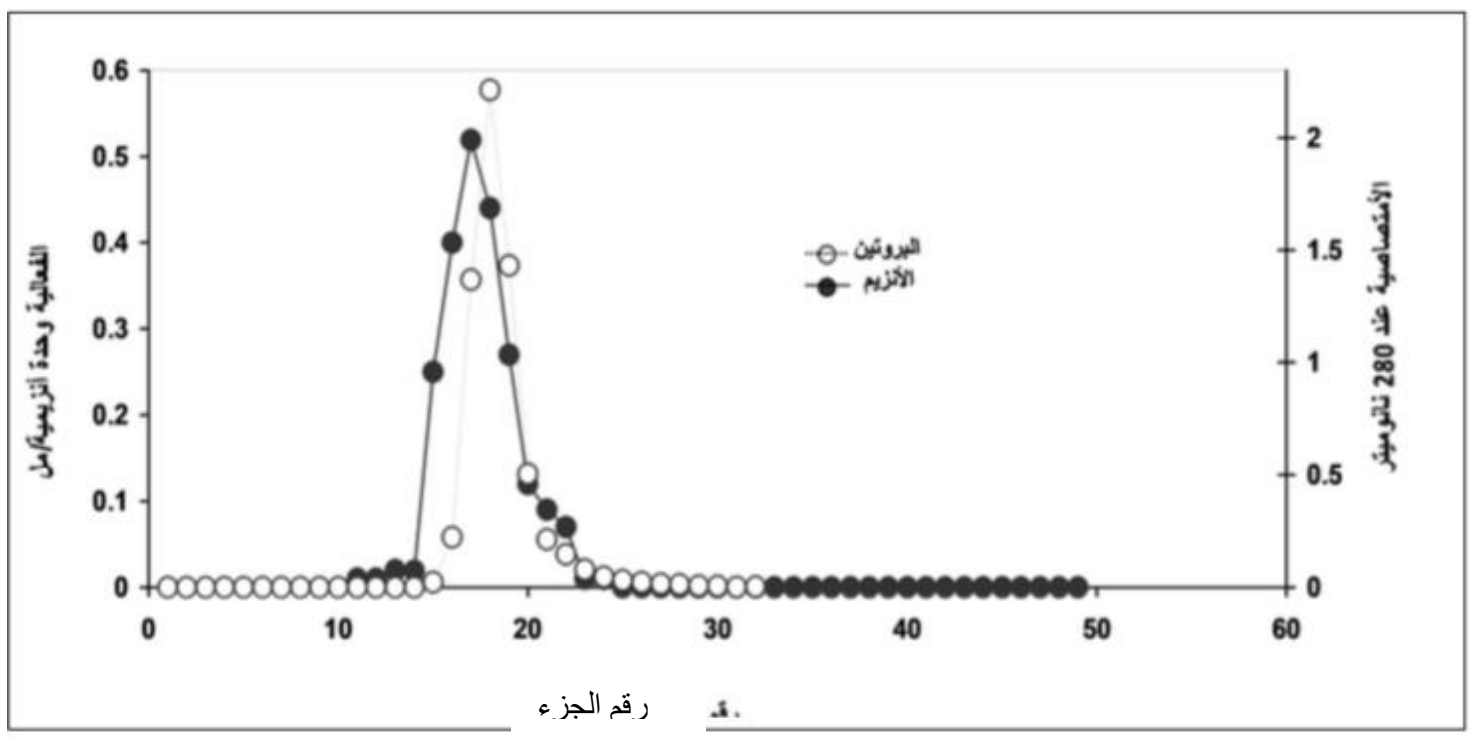

الثكل (2) : نموذج الاسترداد المستحصل من تنقية أنزيم LOX لمصل دم المصابين بالصرع بواسطة كروماتوغرافيا التبادل الأيوني السالب باستخدام

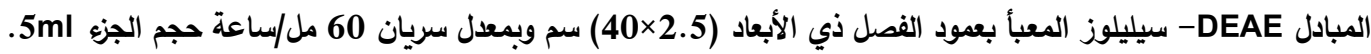

$$
\text { تأثير تركيز الانزيم }
$$

قيست فعالية انزيم الليبواوكسيجنيز (LOX) باستعمال تراكيز مختلفة بأخذ حجوم من الانزيم المنقى جزئيا من مصل دم مرضى

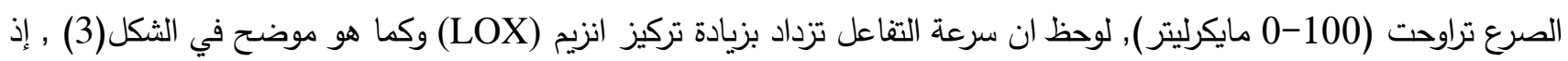
يتقق مع اسس حركيات الانزيم في الادبيات [26,27 على أن سرعة التفاعل المحفز بالإنزيم تتتاسب تناسبا طرديا مع تركيز الانزيم 
عندما تكون المادة الاساس متوفرة في وسط التفاعل, وهذا يتفق مع ما توصل إليه الباحثون [24] بالنسبة للأنزيم المنقى من مرضى الربو.

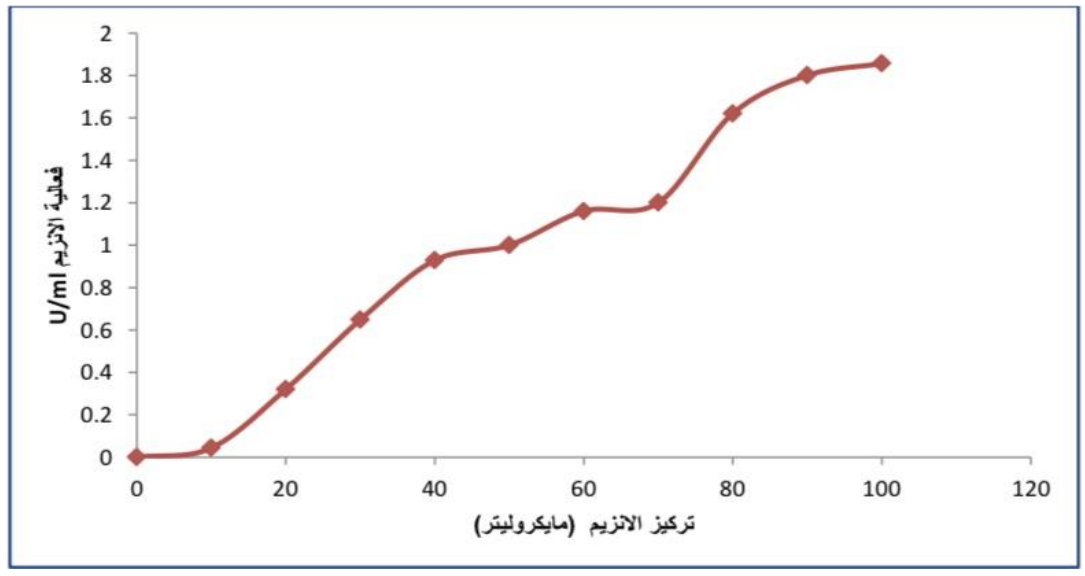

شكل (3) تأثير تركيز الأنزيم على فعالية إنزيم LOX المنقى من مرضى الصرع

تأثير تركيز المادة الاساس .

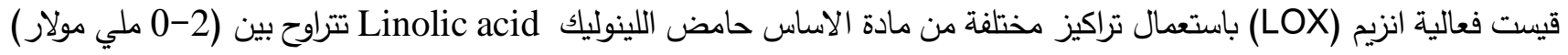
، يبين الشكل (4) ان زيادة تركيز المادة الاساس ادى الى زيادة سرعة التفاعل الانزيمي وصولا الى قيمة معينة لا تحدث بعدها زيادة في سرعة التفاعل مهما زاد تركيز المادة الاساس يطلق على السرعة عند اعلى تركيز من المادة الاساس بالسرعة القصوى (Vmax)

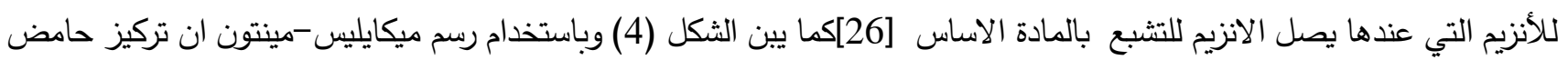

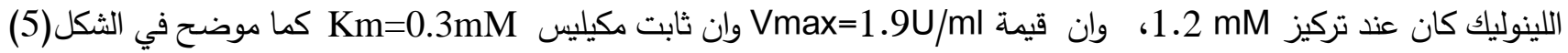

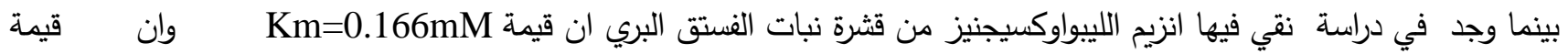
[25] $\mathrm{Vmax}=0.0277 \mathrm{U} / \mathrm{ml}$

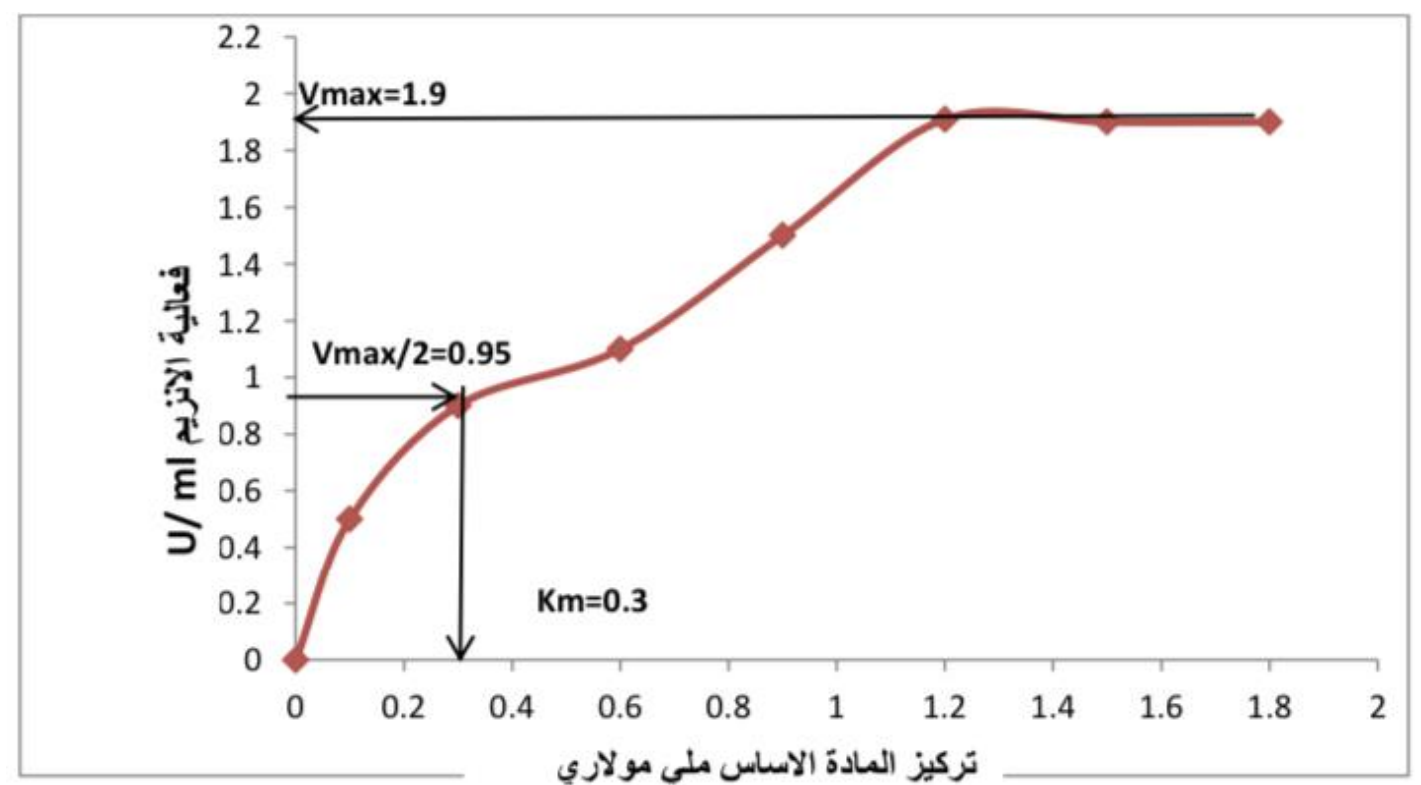

شكل (4) :رسم ميكائيليس-مينتون يوضح تأثير تركيز حامض اللينوليك على سرعة تفاعل انزيم LOX ملاري 


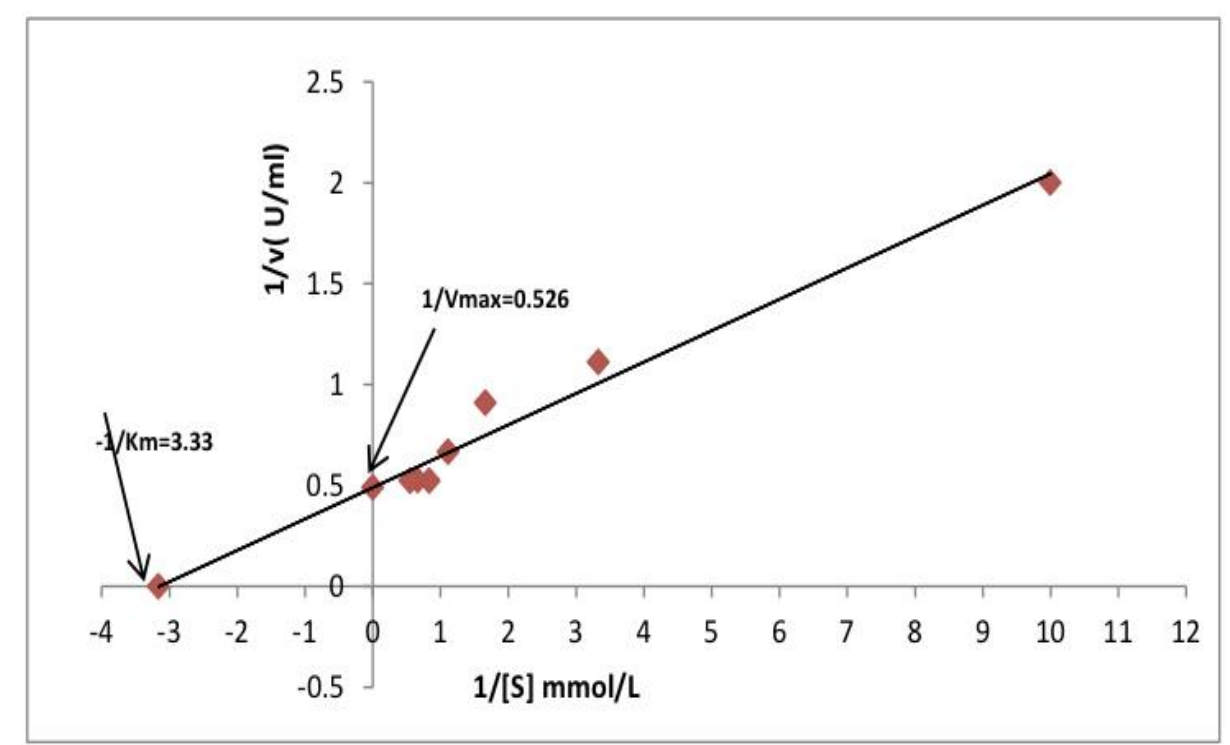

شكل (5) : رسم لاينويفر - بيرك يوضح تاثير تركيز حامض اللينوليك على سرعة تفاعل انزيم LOX

تأثير درجة الحرارة

بدرجات حرارة مختلفة قيست فعالية انزيم الليبواوكسيجنيز واظهرت النتائج المبينة في الثكل (6) ان درجة الحرارة المثلى للإنزيم هي (40C)، انخفضت الفعالية بثكل ملحوظ بعد هذه الدرجة التي تعزى لحصول مسخ (Denaturation) في طبيعة الانزيم نتيجة تفكك الاواصر الهيدروجينية والقوى الاخرى المسؤولة عن الحفاظ على التركيب الرباعي ومن ثم فقدان فعالية الانزيم [21], وهذه النتيجة تتفق مع ما توصل اليه الباحثون [24] لأنزيم الليبواوكسيجنيز المفصول من مصل دم مرضى الربو والباحثين [28] للأنزيم المفصول من دقيق القهح , وفي دراسة بينت ان افضل درجة حرارة لفعالية انزيم الليبواوكسيجنيز المستخلص من الطماطم كانت . [29] $\left(25^{\circ} \mathrm{C}\right)$

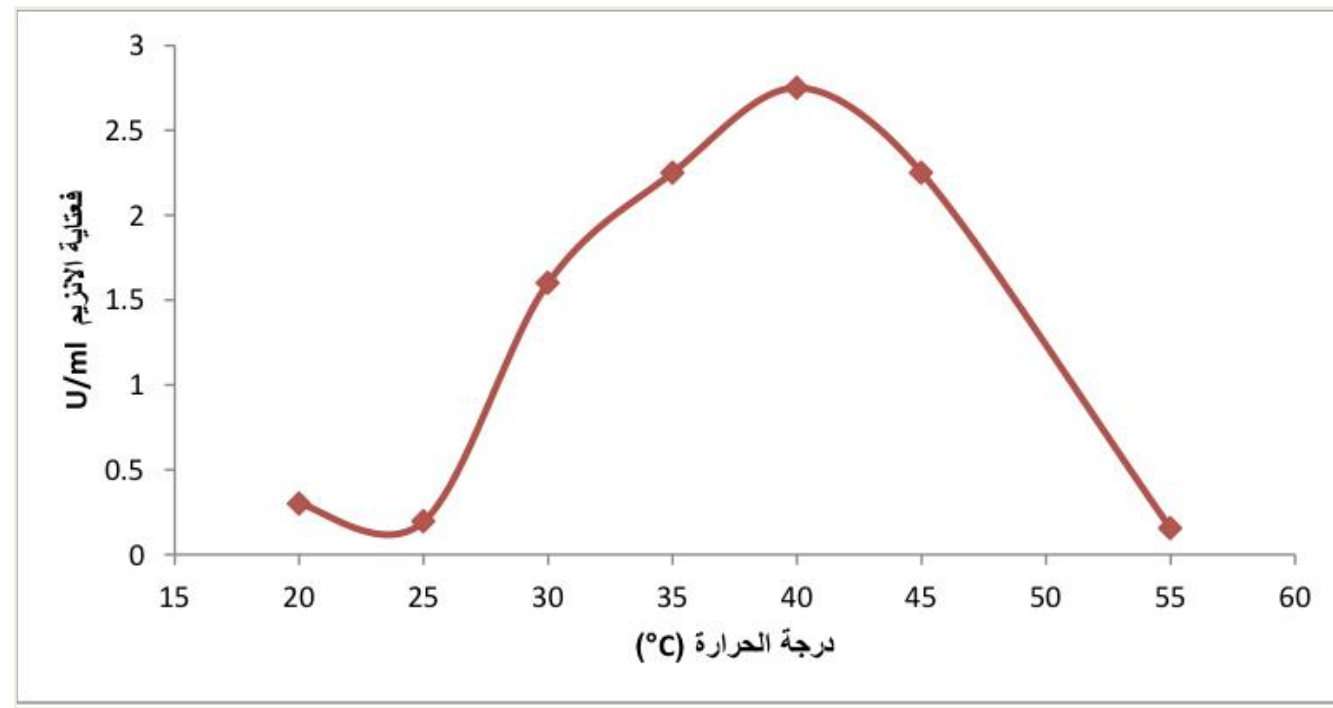

شكل (6) :تأثير درجة الحرارة على فعالية إنزيم LOX المنقى جزئيا من مصل الام

pH تأثير الدالة الحامضية

قيست فعالية انزيم (LOX) في بيئات حامضية مختلفة لمحلول الفوسفات المنظم حيث يوضح الثكل (7) الى ان اعلى فعالية لإنزيم (LOX) كانت عند الدالة الحامضية pH=7.4 , إذ ان كل انزيم لديه دالة حامضية معينة يظهر عنده اعلى فعالية تسمى لئي الدالة الحامضية المثلى Optimum pH [30] وعند استخدام اس هيدروجيني عالي او واطئ جدا يؤدي الى فقدان فعالية الانزيم 
اما بسبب حدوث مسخ او تشوهات لطبيعة الانزيم. كما اشار الباحثون [24] الى ان الدالة الحامضية المثلى لانزيم الليبواوكسيجنيز المعزول من مصل دم مرضى الربو pH=8 بينما كانت للأنزيم المنقى من الفول السوداني تتراوح بين 8 و8.5 [31],أما الأنزيم

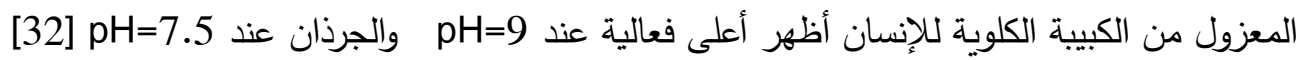

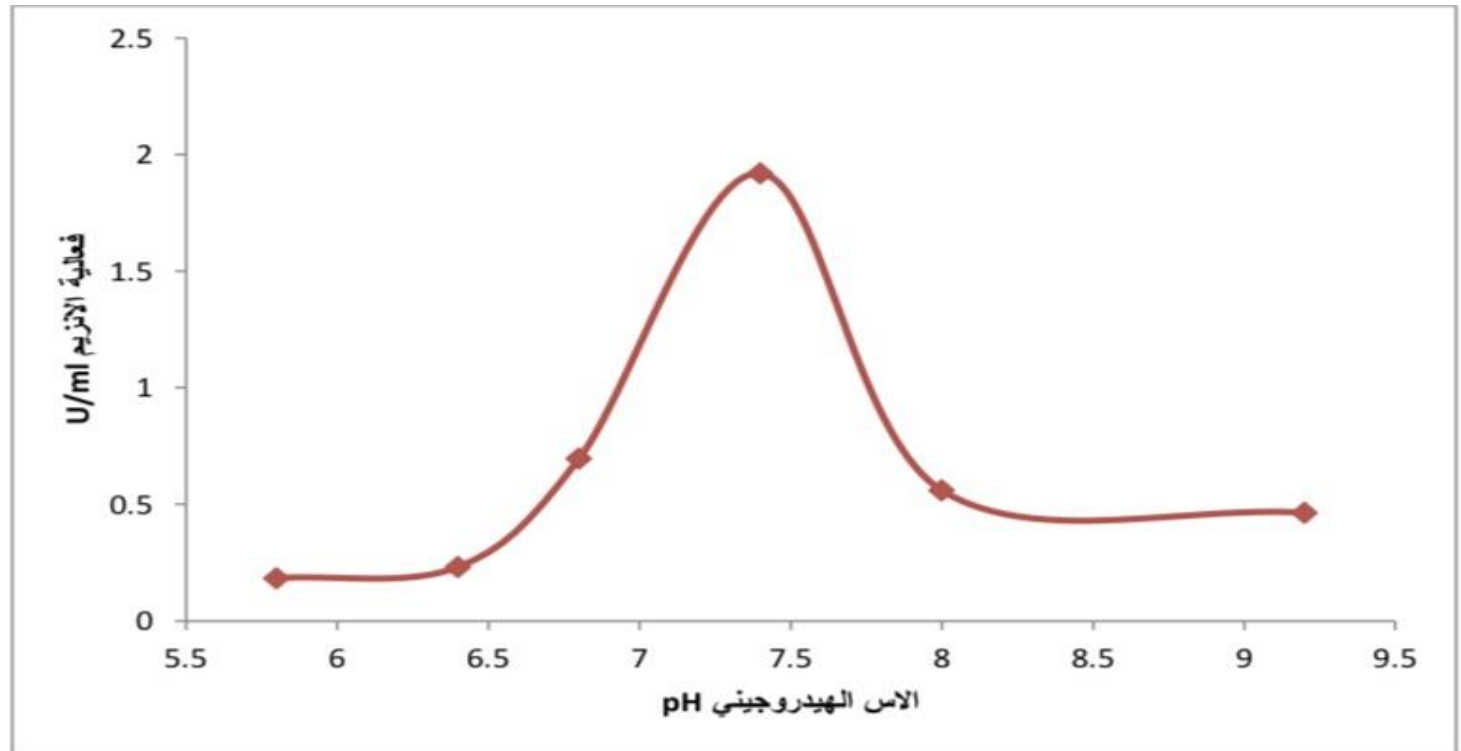

شكل (7) :تأثير الاس الهيدروجيني على فعالية إنزيم LOX

تأثير زمن الحضن :

قيست فعالية انزيم (LOX) بفترات حضن مختلفة واشارت النتائج الموضحة في الثكل (8) , الى ان افضل فعالية لإنزيم كانت عند الدقيقة السابعة من فترة الحضن. وتبين في دراسة نُقي فيها انزيم الليبواوكسيجنيز من لب نبات الفستق البري

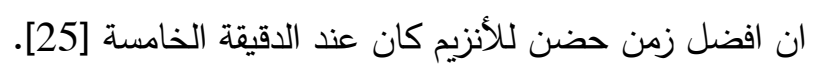

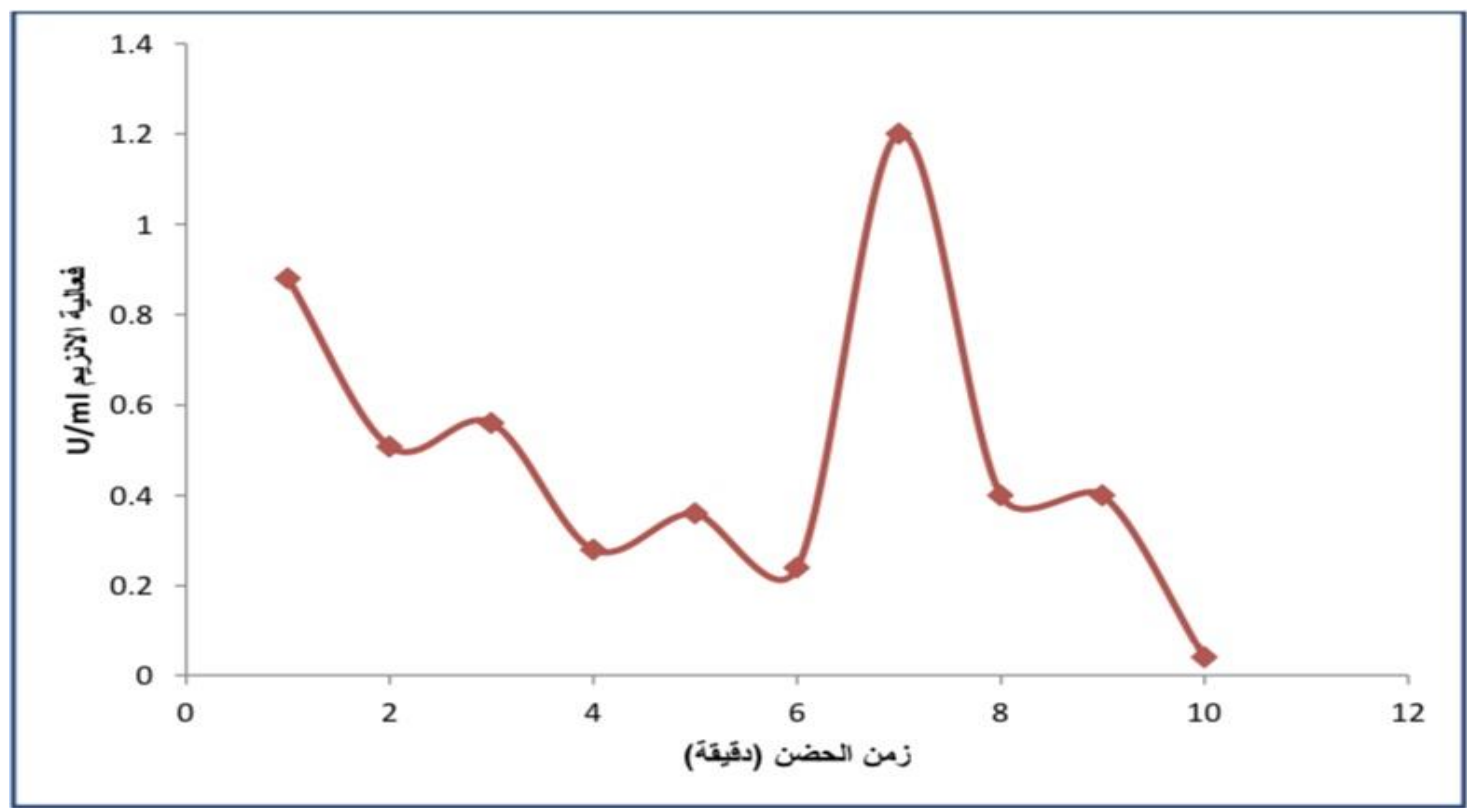

شكل(8): تأثير زمن الحضن على فعالية انزيم LOX 
تأثير زمن التفاعل درس تأثير زمن التفاعل لأنزيم (LOX) بأوقات مختلفة من بدء لتحديد المدة الزمنية المثلى للتفاعل, اشارت النتائج الموضحة في الثكل (9) ان افضل فعالية لإنزيم (LOX) كانت عند الدقيقة الثالثة من بدء التفاعل ثم تبدأ بعدها بالانخفاض وفي دراسة نقي فيها

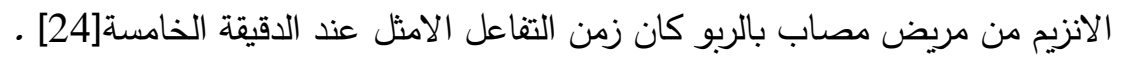

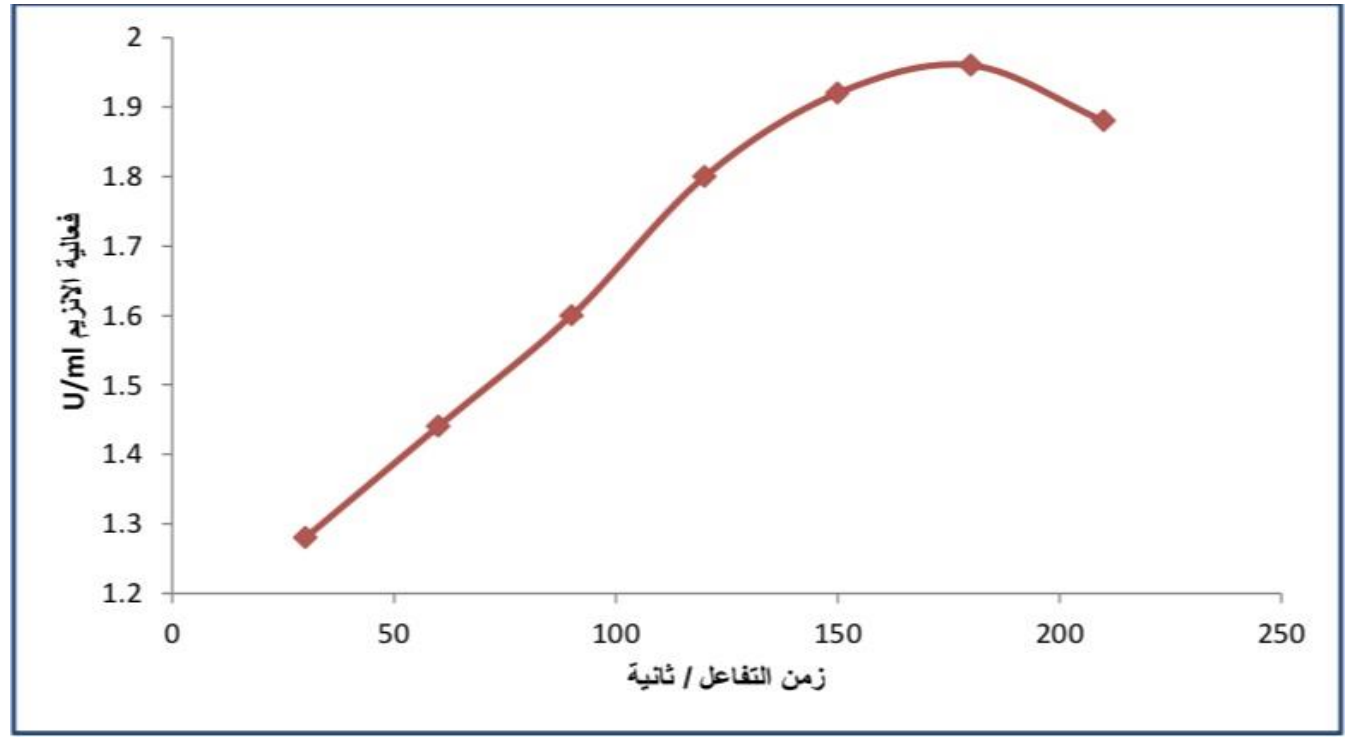

شكل (9) : تأثير زمن التفاعل على فعالية انزيم الليبواوكسيجنيز

3 - دراسة تأثير الادوية المضادة للصرع على فعالية انزيم الليبواوكسيجنيز المنقى جزئيا من مصل دم مرضى الصرع

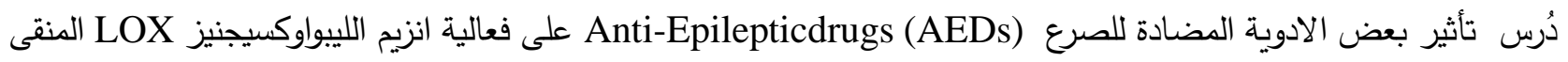

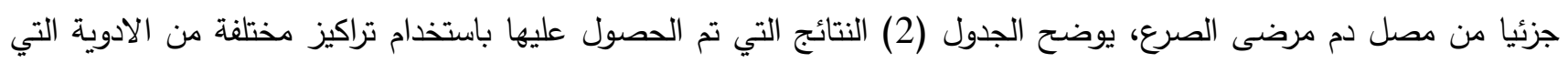
شملت حامض الفالبرويك (الديباكين ) والكاربامازابين (التكريتول ) و اسيتوزولاميد (دياموكس), واعطت هذه الادوية نسب تثبيطية

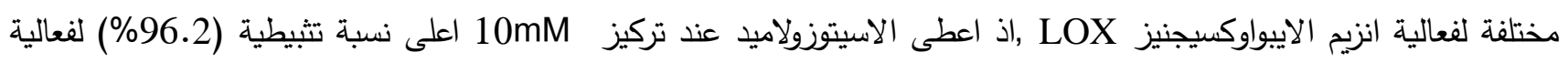
الانزيم مقارنة بالكاربامازين والفالبرويك 95.1 و95.6 الايوليجيز جدول (2) يوضح نسب تثبيط الادوية المضادة للصرع لفعالية انزيم اللييواوكسيجينيز

\begin{tabular}{|c|c|c|c|c|c|c|}
\hline \multicolumn{2}{|c|}{ Valproic acid } & \multicolumn{2}{|c|}{ Carbamazepine } & \multicolumn{2}{|c|}{ Acetozolamid } & \\
\hline اللنشبة المئوية & أنزيعية/ملة الفية & اللنشبية المنوية & أنزيبية/مل وحدة & اللنشبية المئوية & أنزيمية/ملة الفية & التزكيز ملي \\
\hline 0 & 0.185 & 0 & 0.185 & 0 & 0.185 & سيطرة بدون \\
\hline 89.1 & 0.02 & 5.9 & 0.174 & 91.9 & 0.015 & 5 \\
\hline 95.1 & 0.009 & 92 & 0.0139 & 96.2 & 0.007 & 10 \\
\hline 92.4 & 0.014 & 89 & 0.0197 & 81.1 & 0.034 & 15 \\
\hline 95.6 & 0.008 & 89 & 0.0197 & 90 & 0.018 & 20 \\
\hline 74.5 & 0.047 & 92.4 & 0.0139 & 68.6 & 0.058 & 25 \\
\hline 91.3 & 0.016 & 78.9 & 0.039 & -0.06 & 0.179 & 30 \\
\hline 87.0 & 0.024 & 95.1 & 0.009 & 91.9 & 0.0154 & 35 \\
\hline
\end{tabular}




\section{4- دراسة نوع التثبيط للأدوية المضادة للصرع على فعالية انزيم الليبواوكسيجنيز. - A}

20mM Vُرس نوع التثبط لحامض الفالبرويك (Valproic acid ) على فعالية انزيم الليبواوكسيجنيز المنقى جزئيا, بأخذ التركيز الامثل للتثبيط كما في جدول(2) وباستخدام رسم لينويفر - بيرك وكانت قيمة Km ثابتة بدون مثبط وبوجوده 0.3 بينما وجدت قيمة

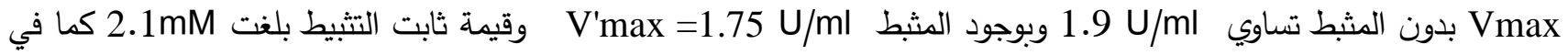
الجدول (3) وان نوع التثبيط غير التنافسي. قد يعزى السبب في تثبيط الانزيم بواسطة حامض الفالبرويك الى امتلاكه لمجاميع فعالة

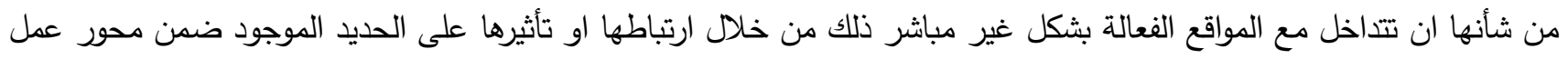

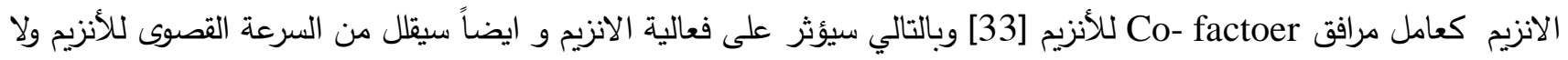

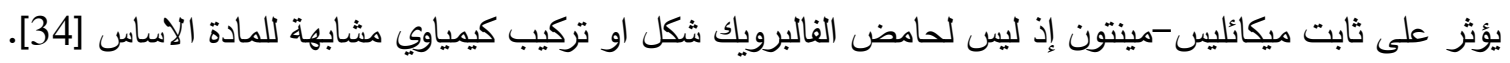

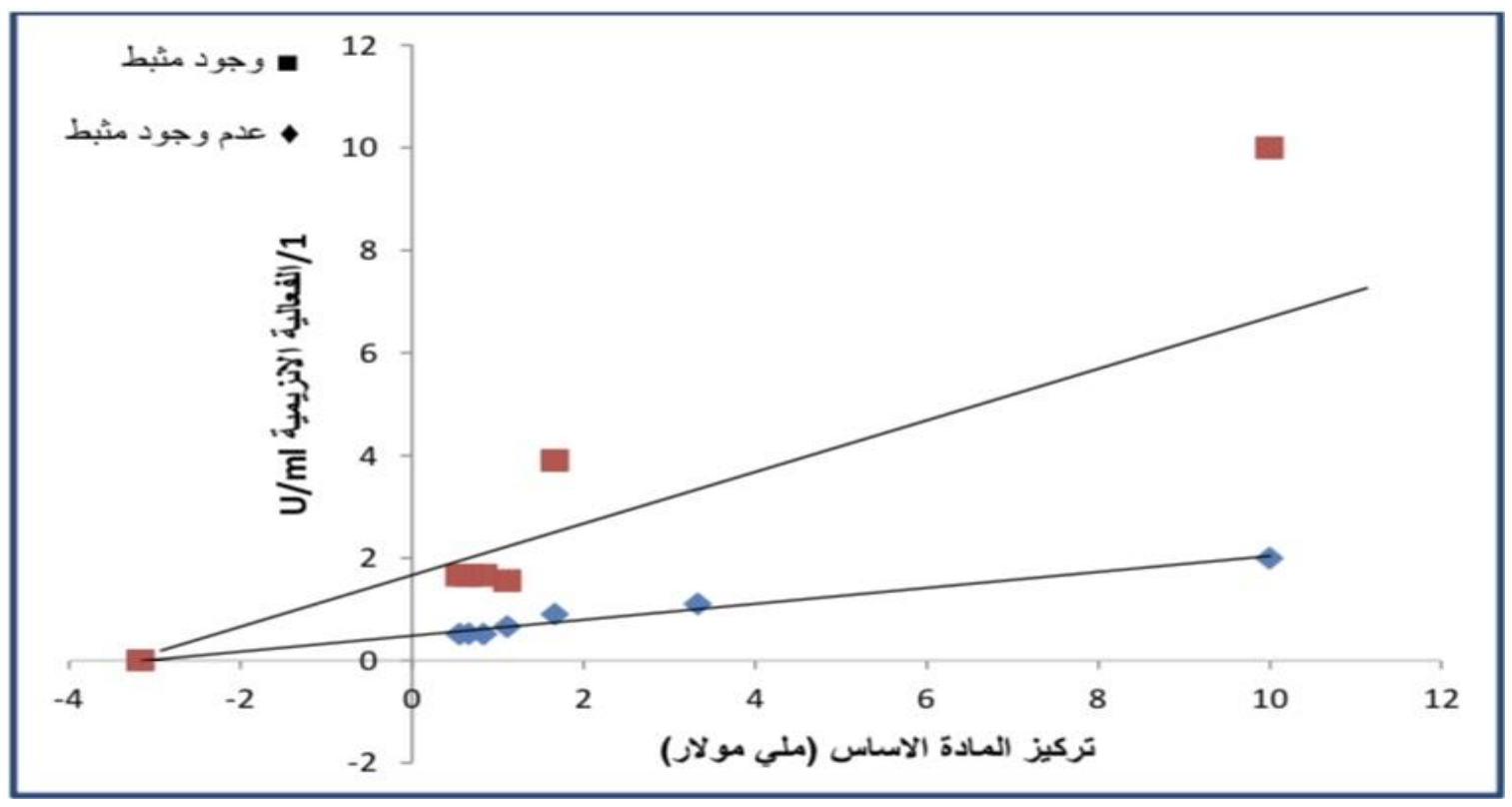

شكل(10): رسم لينويفر - بيرك عند استخدام مشبط حامض الفالبرويك

-B الكاربامازابين -B

اشارت دراسة تأثير الكاربامازابين على فعالية انزيم الليبواوكسيجنيز المنقى جزئيا باعتماد التركيز الامثل للتثبط 35mM جدول(2)

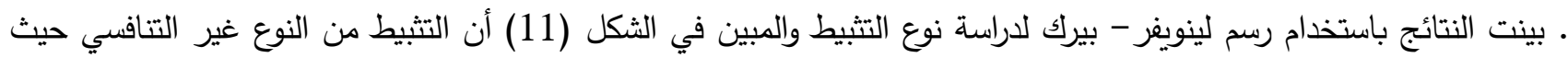

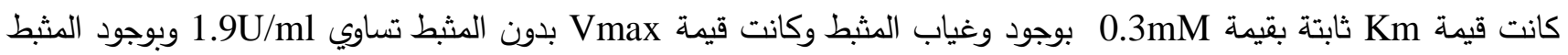
ثابت التثبيط 3.6mM كما هو في الجدول (3) ـ قد يعزى السبب في تتبيط الانزيم بواسطة الكاربامازابين

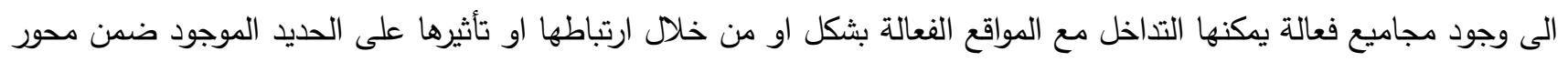

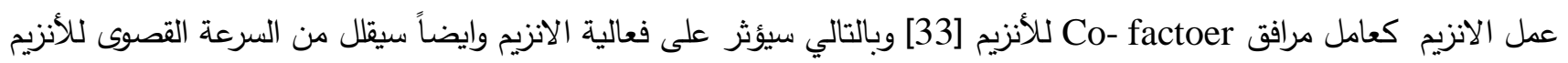

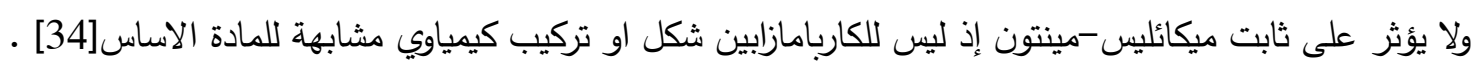




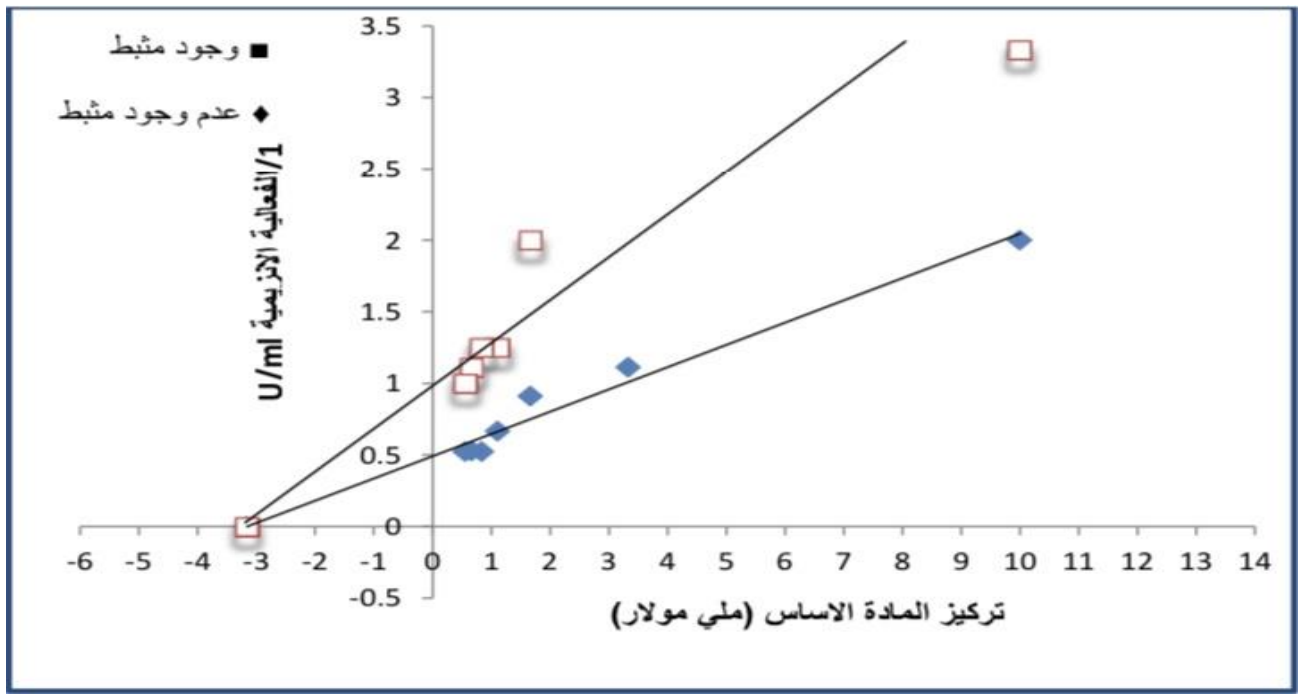

شكل(11): رسم لينويفر - بيرك عند استخدام مثبط الكاربامازابين

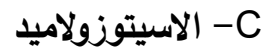

دُرس تأثير دواء الاسيتوزولاميد بوصفه مثبط لفعالية انزيم الليبواوكسيجنيز وباستخدام رسم لينويفر-بيرك لبيان نوع التثبيط

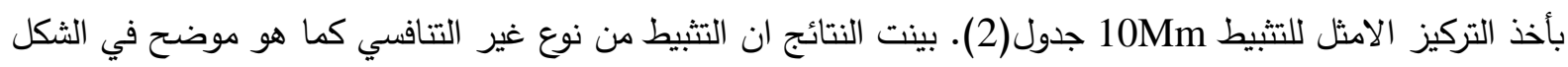

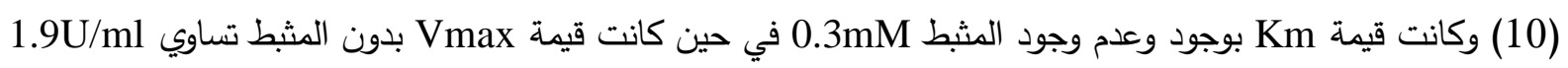

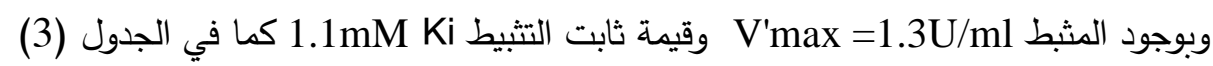
قد يعزى السبب في تتبيط الانزيم بواسطة الاسيتوزولاميد احتواء الدواء مجموعة مجاميع فعالة لها القابلية على التداخل مع تع المواقع الفعالة بثكل غير مباشر او من خلال ارتباطها او تأثيرها على الحديد الموجود ضمن محور عمل الانزيم كعامل

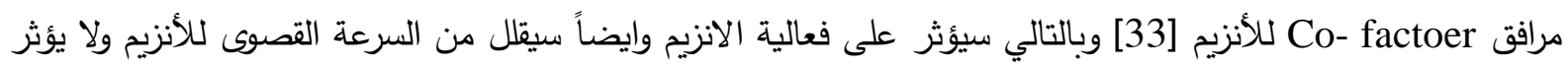

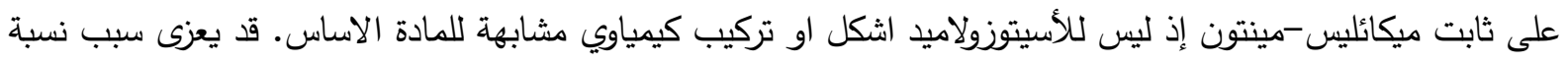
التثبيط العالية لهذا الدواء لوجود اكثر من مجموعة وظيفية فعالة واحدة في هذا المركب عند مقارنته بمحتوى الادوية الاخرى

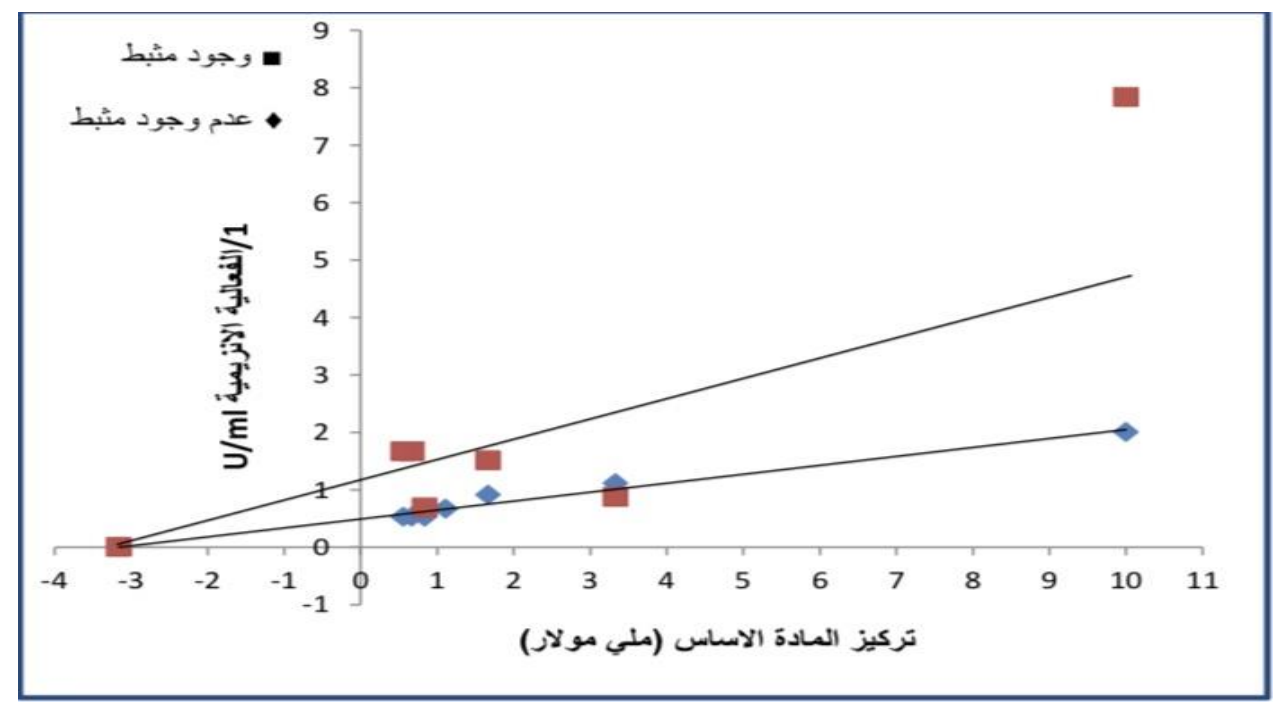

شكل(12): رسم لينويفر - بيرك عند استخدام مثبط (اسيتوزولاميد) 
ويبين الجدول(3) المتغيرات الحركية الانزيم بوجود وعدم وجود المثبطات جدول (3) : المتغيرات الحركية و نوع التأثير التثبيطي للعقاقير المستخدمة في توديط تثبيط أنزيم LOX المنقى من دم المصابين بالصرع

\begin{tabular}{|c|c|c|c|c|c|c|}
\hline نوع الشبيط & $(\mathrm{mM}) \mathrm{Ki}$ & $\begin{array}{c}\text { V'max } \\
\text { (unit/ml) } \\
\text { بوجود المثبط }\end{array}$ & $\begin{array}{l}\text { Vmax } \\
\text { (unit/ml) } \\
\text { بون المثبط }\end{array}$ & $\begin{array}{c}\mathrm{K}^{\prime} \mathrm{m} \\
(\mathrm{mM}) \\
\text { بوجود المثنبط }\end{array}$ & $\begin{array}{l}\text { (mM) Km } \\
\text { بدون المثبط }\end{array}$ & الامثلّل اللشتبيط ملثي مولار) \\
\hline تنافير & 1.1 & 1.3 & 1.9 & 0.3 & 0.3 & Acetolazamide $-10 \mathrm{mM}$ \\
\hline تنافير & 3.6 & 0.95 & 1.9 & 0.3 & 0.3 & Carbamazepin $-35 \mathrm{mM}$ \\
\hline تنافير غير & 2.1 & 1.75 & 1.9 & 0.3 & 0.3 & Valproic acid $-20 \mathrm{mM}$ \\
\hline
\end{tabular}

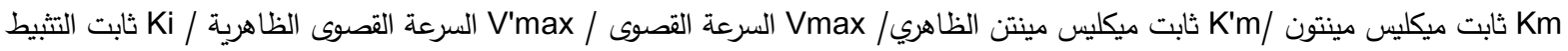

Conclusions الاستنتاجات

تم الحصول على حزمة بروتينية واحدة باستخدام تقنية كروموتوغرافيا التبادل الايوني • وبينت النتائج أن أعلى فعالية للإنزيم كانت عند درجة حرارة 40 وزمن حضن عن الدقيقة السابعة ودالة حامضية pH=7.4 وزمن تفاعل عند الدقيقة الثالثة و كان تركيز المادة الاساس (حامض اللينوليك) الامثل 1.2 mM , وباستخدام معادلة لينويفر -بيرك وميكليس مينتون اظهرت قيمة السرعة . Km =0.3 mM وان ثابت ميكليس مينتن Vmax = أعطى الاسيتوزولاميد عند 10mM أعلى نسبة تتبيطية(96.2\%) لفعالية الانزيم مقارنة بالأدوية الاخرى واعطى دواء حامض مانسئ الفالبرويك نسبة تثبيطية (20mM 205.6) عند تركيز اعطى الكاربامازابين نسبة تثبيطية (95.1\%) عند تركيز

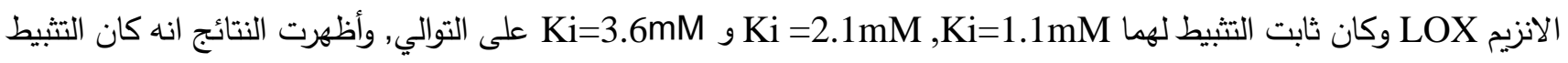
غير تنافسي لجميع الأدوية المستخدمة.

\section{Acknowledgements الشكر والامتنان}

اتقدم بالثكر الجزيل الى قسم الكيمباء/ كلية التربية للعلوم الصرفة/جامعة الموصل بتوفير المختبرات البحثية والمستلزمات الضرورية لأجراء هذا البحث النغ

\section{References المصادر}

1- Mac, T. L., Tran, D. S., Quet, F., Odermatt, P., Preux, P. M., \& Tan, C. T. (2007). Epidemiology, aetiology, and clinical management of epilepsy in Asia: a systematic review. The Lancet Neurology, 6(6), 533-543.

2- Hesdorffer, D. C., Benn, E. K., Cascino, G. D., \& Hauser, W. A. (2009). Is a first acute symptomatic seizure epilepsy? Mortality and risk for recurrent seizure. Epilepsia, 50(5), 1102-1108.

3-Daroff, R.B.; Jankovic, J.; Mazziotta, J.C.; Pomeroy, S.L. (2016) Bradley's Neurology in Clinical Practice E-Book; Elsevier Health Sciences; ISBN 9780323287838.

4-Ray, A., Tao, J. X., Hawes-Ebersole, S. M., \& Ebersole, J. S. (2007). Localizing value of scalp EEG spikes: a simultaneous scalp and intracranial study. Clinical neurophysiology, 118(1), 69-79.

5- Granata, T., Marchi, N., Carlton, E., Ghosh, C., Gonzalez-Martinez, J., Alexopoulos, A. V., \& Janigro, D. (2009). Management of the patient with medically refractory epilepsy. Expert review of neurotherapeutics, 9(12), 1791-1802. 
6- Helbig, I., Scheffer, I. E., Mulley, J. C., \& Berkovic, S. F. (2008). Navigating the channels and beyond: unravelling the genetics of the epilepsies. The Lancet Neurology, 7(3), 231-245.

7- Kjeldsen, M. J., Corey, L. A., Christensen, K., \& Friis, M. L. (2003). Epileptic seizures and syndromes in twins: the importance of genetic factors. Epilepsy research, 55(1-2), 137-146.

8- Siedow, J. N. (1991). Plant lipoxygenase: structure and function. Annual review of plant biology, 42(1), 145-188.

9- Porta, H., \& Rocha-Sosa, M. (2002). Plant lipoxygenases. Physiological and molecular features. Plant physiology, 130(1), 15-21.

10- Bankova, L. G., \& Boyce, J. A. (2018). A new spin on mast cells and cysteinyl leukotrienes: Leukotriene E4 activates mast cells in vivo. Journal of Allergy and Clinical Immunology, 142(4), 1056-1057.

11- Drazen, J. M., Israel, E., \& O'Byrne, P. M. (1999). Treatment of asthma with drugs modifying the leukotriene pathway. New England Journal of Medicine, 340(3), 197-206.

12- Lenz, Q. F., Arroyo, D. S., Temp, F. R., Poersch, A. B., Masson, C. J., Jesse, A. C., ... \& Mello, C. F. (2014). Cysteinyl leukotriene receptor (CysLT) antagonists decrease pentylenetetrazolinduced seizures and blood-brain barrier dysfunction. Neuroscience, 277, 859-871.

13- Gorter, J. A., Aronica, E., \& Van Vliet, E. A. (2019). The Roof is Leaking and a Storm is Raging: Repairing the Blood-Brain Barrier in the Fight Against Epilepsy. Epilepsy currents, 19(3), 177181.

14- Simmet, T., \& Tippler, B. (1990). Cysteinyl-leukotriene production during limbic seizures triggered by kainic acid. Brain research, 515(1-2), 79-86.

15- Kim, H. C., Jhoo, W. K., Bing, G., Shin, E. J., Wie, M. B., Kim, W. K., \& Ko, K. H. (2000). Phenidone prevents kainate-induced neurotoxicity via antioxidant mechanisms. Brain research, 874(1), 15-23.

16-Samiappan, R. (2013). Insertion of transmembrane 5-lipoxygenase activating protein (FLAP) into nanodiscs towards structure function studies of complex formation with soluble proteins.

17- Bacchus, R., Kilshaw, B. H., Madkour, M., Bassam, S. A., \& Farhan, B. A. (1980). Preliminary studies on a reference range for Saudi Arabian males: 1. Serum uric acid. Saudi Medical Journal, 1(3), 160-163.

18- Wilson, S. S., Guillan, R. A., \& Hocker, E. V. (1972). Studies of the stability of 18 chemical constituents of human serum. Clinical chemistry, 18(12), 1498-1503.

19- Schacterle, G. P., GP, S., \& RL, P. (1973). A simplified method for the quantitative assay of small amounts of proteins in biologic material.

20- Shastry, B. S., \& Rao, M. R. (1975). Studies on lipoxygenase from rice bran. Cereal Chemistry, 52(5), 597-603.

21- Robyt F.J. \& White J. B. (2001). "Biochemical techniques ,theory and Practice " . Brookes/Cole publishing company, Monterey, California.

22- Plummer, T.D. (1978)."An Introduction of Practical Biochemistry". 2nd ed., McGraw-Hill Book Co., U.K., pp : 48, 53, 174, 270, 274.1 
23- Befani, O., Grippa, E., Saso, L., Turini, P., \& Mondovi, B. (2001). Inhibition of monoamine oxidase by metronidazole. Inflammation Research, 50(2), 136-137.

24- Kamal, H. R., \& Hasan, M. B. (2019). Isolation and Purification of Lipoxygenase from the Serum of Bronchial Asthma Patient and Studying the Effect of Natural Products of Horse Tail (Equisetum arvense. L) Plant on it's Activity. Rafidain Journal of Science, 28(4), 76-93.

25-Al-Abbasi, Omar Yunus Muhammed (2013). " Isolation and Purification of Lipase and Lipoxygenase from Pistacia khinjuke and Investigation their Affinity toward certain Inhibitors in Mice with Induced Diabetes. PhD thesis, College of Education, University of Mosul

26-Flayeh, Khawla Ahmed. (2006). An Introduction to Biochemistry, Second Edition, Dar Al-Kutub for Printing and Publishing, University of Mosul, pp. 156-159

27- Murray, K., Rodwell, V., Bender, D., Botham, K. M., Weil, P. A., \& Kennelly, P. J. (2009). Harper's illustrated biochemistry. 28 (p. 588). New York: McGraw-Hill.

28-Barone, R., Briante, R., D'Auria, S., Febbraio, F., Vaccaro, C., Del Giudice, L., ... \& Nucci, R. (1999). Purification and characterization of a lipoxygenase enzyme from durum wheat semolina. Journal of agricultural and food chemistry, 47(5), 1924-1931.

29- Yilmaz E.(2001)."Kinetic Studies With Crude Tomato Lipoxygenase". Turk. J. Agric. For., 25 : 291-296.

30-Lagarde, M., Croset, M., Authi, K. S., \& Crawford, N. (1984). Subcellular localization and some properties of lipoxygenase activity in human blood platelets. Biochemical Journal, 222(2), 495500.

31-Muhaisen, Ibtisam Karim, Yahya, Iyad Nafi ', Al-Araji, Sanad Baqer. (2008). Characterization of purified extracted lipoxygenase from Arachis hypogaea L. peanut seeds. Damascus University Journal for Basic Sciences, 24 (2): 135-162

32- Sraer, J., Rigaud, M., Bens, M., Rabinovitch, H., \& Ardaillou, R. (1983). Metabolism of arachidonic acid via the lipoxygenase pathway in human and murine glomeruli. Journal of Biological Chemistry, 258(7), 4325-4330.

33- Gilbert, N. C., Bartlett, S. G., Waight, M. T., Neau, D. B., Boeglin, W. E., Brash, A. R., \& Newcomer, M. E. (2011). The structure of human 5-lipoxygenase. Science, 331(6014), 217-219.

34- Elghoul, H. H. M. (2016). Comparative Study of Carbamazepine (CBZ) Versus Valproic Acid (VPA) Effect on Liver Function and Lipid Profile in Epileptic Children (Gaza Strip) (Doctoral dissertation, Al-Azhar University).

35- Chiaramonte, N., Romanelli, M. N., Teodori, E., \& Supuran, C. T. (2018). Amino acids as building blocks for carbonic anhydrase inhibitors. Metabolites, 8(2), 36 